\title{
Sustainable development international aspect
}

\author{
Vladimir Sulimin, Vladislav Shvedov and Maya Lvova \\ Ural State University of Economics, Yekaterinburg, Russia
}

\begin{abstract}
The concept of sustainable development, adopted in 2015 by the United Nations General Assembly, contains 17 goals and almost 170 related tasks, the solution of which will improve the three most important spheres of society - economic, social and environmental. 193 countries, whose leaders started the further adaptation of the SDGs to the realities and capabilities of specific states signed the UN resolution. The authors consider the key principles of sustainable development in the world economy, achievements and problems identified implementing the Concept of sustainable development. An analysis of the activities of the world community to support the sustainable development strategy in the economic crisis caused by the COVID-19 pandemic is presented.
\end{abstract}

\section{Introduction}

The fundamental principles of sustainable development are: 1) meeting the needs of the living generation without prejudice to the vital functions of future generations; 2) the introduction of restrictions in the exploitation's field of natural resources; 3 ) meeting the basic needs of each individual; 4) help in the realization of the hopes of any person for a prosperous existence; 5) coordination of the size and growth rate of the population with the totality of material and energy resources and properties of ecosystems; 6) versatility; 7) interconnection, the indivisibility of the SDGs; 8) partnership ways to overcome problems; 9) considering the individual abilities of a person in attracting him to labor activity [2, p. 326].

Implementing the principles is based on the understanding that the development of humanity is limited not only by energy sources and mineral resources but by the totality of the planet's conditions for the development of biological systems.

Objectively assessing the limited and gradual depletion of natural resources, environmental pollution, the rapid growth of the world's population, many foreign scientists (Donell N. Meadows, Dennis L. Meadows, Yergen Randers, and William W. Behrens III) have attempted to create models of social life under the influence of on him these factors. The specialists had two goals: to limit the demographic and economic growth of civilization; develop an action plan after reaching growth limits.

Having theoretically studied the consequences of sped up industrialization, high rates of population growth, environmental degradation, and the lack of opportunities to restore nonrenewable resources, the researchers concluded that the human population is expected to have a sharp, sudden reduction in production capacity, a significant drop in living standards, which will lead to a significant reduction in the population. Humanity can change the identified 
trends, create favorable conditions for the preservation and development of economic and environmental spheres, meet the basic needs of every inhabitant of the planet $[1, \mathrm{p} .180]$.

\section{Materials and methods}

One of the most important issues in implementing of the SDGs is the financing of national action programs by mobilizing the internal resources of countries: improving the tax system, attracting private investment. The solution to this problem is today at a low level in the African states, because of a significant decrease in the volume of taxes collected.

In all countries that have ratified the Concept, they pay serious attention to combating climate threats, limiting greenhouse gas emissions, which lead to irreversible consequences for the planet's ecology, contributing to an increase in the global average temperature to unacceptable values. Combining efforts of over 190 countries to implement the ecological part of the Concept has weak points. Each state forms a policy in this direction independently, for violation of the order of actions no sanctions are provided [3, p.220].

At the global level, there are many achievements in several areas. Summing up the results of 2018 and comparing it with the early 2000s, the UN Secretary General noted: improving obstetrics; decrease in infant mortality rates; reducing the number of people living with HIV and people living with tuberculosis and tropical diseases; noticeable growth in the number of users of various types of energy; reduction of losses of forest resources; an increase in the protected areas and areas of the seas and oceans.

We still consider the following problems unsolved: hunger; a reduction in funds for agriculture in developing countries; many deliberate, independent and voluntary deprivation of life by people; an increase in the number of individuals with malaria; low rates of development of women because of gender inequality; social insecurity of many people; low level of knowledge of a very large number of children in mathematics and reading; the rapid decline in world fish stocks and areas of fertile soil; in over 40 countries, the level of legal protection of citizens does not meet international requirements; insufficient amounts of funds allocated for development in most countries [6, p.190].

\section{Results and discussions}

The global community looks at sustainable development in a new way in connection with the deep economic crisis provoked by the coronavirus pandemic.

Two areas play a special role in sustainable development - IT - technologies and the environmental sector. Digitalization (information and communication goods and services, online platforms, sharing) significantly transforms the way the economy functions and social relationships. Ecological economy (technologies for rational use of energy resources, energy resources of processes that exist on the planet constantly, renewal of used resources, work of enterprises of the type "production / use / reuse of waste", maximum use of the resource potential of lands in agriculture, purposeful use of forests) reduces risks and threats to the environment.

Digitalization ensures the interconnection of the economy and social life. The ecological component contributes to economic growth by minimizing harm to the environment through introducing technologies for the extraction of energy from inexhaustible or renewable sources, the use of environmentally friendly materials. Now in the world there is no possibility of widespread use of the global potential of digitalization because of the low competence in this area of most of the population, even in highly developed countries of the European Union, which during the pandemic can transfer some sectors of the economy to online management $[4$, p. 15$]$. 
The governments of many countries called on the world community not to abandon the implementation of the sustainable development strategy in the crisis's context caused by the pandemic: develop clean energy technologies; support small and medium-sized businesses; eliminate protectionism in the drug trade; write off the debts of developing countries, provide them with preferential loans; coordinate the work of the central financial and credit organizations of the countries taking part in the Concept; waive sanctions; adhere to previously established development priorities; support investments in low-carbon development, support the conversion of kinetic energy of air masses into energy for economic activities; to protect the surrounding nature; restore forest funds; to provide healthy food for people, beneficial effects on food of the environment; support the development of the economy on local resources; to intensify investments in environmentally friendly transport systems, regenerative energy, restoration of buildings without violating the integrity of the structure, scientific activity and innovative technologies [7, p.40].

The anti-crisis strategy aimed at maintaining and strengthening the course of sustainable development was based on the following principles:

- priority aspect - the health of every individual living on the planet;

- provision of economic help to the population;

- targeted support of personnel (not management) of corporations and companies;

- development of large-scale measures to counter climate and financial risks;

- providing individual help to people whose health is negatively affected by climatic risks;

- protection and conservation of nature as a source of human health;

- support of mutual understanding based on common interests and objectives;

- joint opposition to forms of government based on unlimited control of power by the individual.

\section{Conclusions}

A new model of social prosperity is proposed, including an economy based on reducing energy and carbon intensity, protecting the diversity of life in all its manifestations, changing food production, and green recovery. Because of implementing this model, new jobs will appear, which will stimulate economic growth and lead to an increase in the well-being of all people living on Earth.

A system of measures has been developed to restore the economy and improve climatic indicators: greening buildings, communications, engineering communications; increasing the resource efficiency of buildings; restoration of groups of interrelated elements formed because of the interaction of the unification of organisms and the surrounding world; investments in the restoration of biodiversity on land, in rivers, seas, oceans.

We pay particular attention to the problems that have arisen in connection with the pandemic in the civil air transportation system. Countries need to support the production and use of aviation biofuels, stimulate the renewal of the population of passenger aircraft assigned to international airlines; an increase in funding for theoretical and practical developments in this area; digitalization of air traffic management; increasing the possibility of maintaining the operability of airports in emergencies.

Big business of the United States of America and Europe is actively involved in the development of measures to overcome the crisis and continue the course towards sustainable development, investing in green energy. Countries need to help small and medium-sized businesses, and not giant corporations [5, p. 1572].

Despite many statements, proposals and programs, it is still impossible to talk about the effectiveness of the measures announced by the governments of many countries of the world to overcome the consequences of the coronavirus pandemic: green recovery, a change in the economic course are proceeding at a slow pace. The unprecedented unanimity of the world 
community about the need to continue the course of sustainable development gives hope that in time we will solve all the problems and achieve the goal.

\section{References}

1. A.A. Ignatov, S.V. Mikhnevich, I.M. Popova, E.A. Safonkina, A.G. Sakharov, A.V. Shelepov, Bulletin of International Organizations 14(1) 164 (2018)

2. A.Yu. Kruglov, From Millennium Development Goals to Sustainable Development Goals: Towards Forming Shared Responsibility in Education, Collection of Articles of the X International Scientific and Practical Conference «Scientific School of T.I. Shamova: methodological, theoretical and technological resources for the development of educational systems», Moscow: 5 for knowledge, 324 (2018)

3. T.A. Lanshina, V.A. Barinova, A.D. Loginova, E.P. Lavrovsky, I.V. Monday, Bulletin of International Organizations 14(1), 207 (2019).

4. N.A. Lvov, N.S. Voronova, Problems of the modern economy 3, 12 (2018)

5. V.I. Salygin, R.V. Petrova R.K. Mustafinov, Ekonomicheskie Otnosheniya 9(3), 1563 (2019)

6. A.G. Sakharov, O.I. Kolmar, Bulletin of International Organizations: Education, Science, New Economy 1, 189 (2019)

7. L.S. Khudyakova, World Economy and International Relations 62(7), 38 (2018)

8. A. Donkor, T. Luckett, S. Aranda, V. Vanderpuye, J.L. Phillips, BMC Health Services Research 21(1) (2021). doi:10.1186/s12913-021-06274-X

9. G. Garavito, R. Clavijo, P. Luengas, P. Palacios, M.H. Arias, J. of Ethnobiology and Ethnomedicine 17(1), (2021). doi:10.1186/s13002-021-00453-0

10. J. Guo, M. Chen, X. Sun, Z. Wang, J. Xue, PLoS ONE 15(12 December) (2021). doi:10.1371/journal.pone.0242981

11. A. R. Lindsay, J. N. Sanchirico, T. E. Gilliland, R. Ambo-Rappe, J. Edward Taylor, N.C. Krueck, P. J. Mumby, Evaluating sustainable development policies in rural coastal economies. Proceedings of the National Academy of Sciences of the United States of America, 117(52), 33170 (2021). doi:10.1073/PNAS.2017835117

12. F. N. Mabe, E. Mumuni, N. Sulemana, Agriculture and Food Security 10(1), (2021). doi:10.1186/s40066-020-00281-7

13. J. E. Masson, I. Soustre-Gacougnolle, M. Perrin, C. Schmitt, M. Henaux, C. Jaugey, R. Lassablière, Humanities and Social Sciences Communications 8(1), (2021). doi:10.1057/s41599-020-00693-7

14. K. Selvaranjan, J. C. P. H. Gamage, G. I. P. De Silva, S. Navaratnam, J. of Building Engineering, 43(2021). doi:10.1016/j.jobe.2021.102614

15. A. Tengia-Kessy, G. C. Msalale, BMC Pregnancy and Childbirth 21(1), (2021). doi:10.1186/s12884-021-03741-5 